\section{PREVENTING FALLS}

\section{Not at the expense of osteoporosis care}

Järvinen et al remind us that falls assessment is too often ignored in people at high risk of fractures. ${ }^{1}$ However, we believe that falls assessment and prevention must be in addition to, and not at the expense of, osteoporosis treatment. The British Orthopaedic Association advocates a dual approach to fracture prevention, ${ }^{2}$ and indicators supporting both have been submitted for inclusion within the quality outcomes framework (QOF) in the UK.

We have high quality evidence for the secondary prevention of hip fractures with generic treatments endorsed as cost effective by the National Institute for Health and Clinical Excellence (NICE). We need more robust evidence linking falls interventions to the same outcomes. The studies listed by Järvinen et al do not support a claim for a $50 \%$ fracture reduction in community settings. This is the thrust of the paper by Gates and colleagues. ${ }^{3}$ Individual studies have shown that single and multifaceted interventions can be effective in reducing falls, ${ }^{1}$ but we require further research on their costeffectiveness. ${ }^{4}$

The priority for reducing fractures lies currently with secondary fracture prevention, in which care recommended in guidelines is delivered to less than one in five in the UK. ${ }^{5}$ Far from a change in direction, we need to combine falls assessment and prevention with a wider adoption of fracture liaison services and osteoporosis indicators within the QOF. Jonathan Bayly associate lecturer, Faculty of Education Health and Sciences, University of Derby, Derby DE22 1GB jonathan@bayly.org

Tahir Masud consultant physician, Nottingham University Hospitals NHS Trust, Nottingham NG5 1PB

Competing interests: JB was the lead author for the recent osteoporosis submission to the QOF review process on behalf of the National Osteoporosis Society and a joint author for the British Geriatric Society's submission on falls. Both he and TM have received educational support, honorariums, and travel expenses for lectures on falls and bone health and advisory board work from a number of pharmaceutical companies with an interest in these disease areas.

1 Järvinen TLN, Sievanen H, Khan KM, Heinonen A Kannus P. Shifting the focus in fracture prevention from osteoporosis to falls. BMJ 2008;336:124-6. (19 January.)

2 British Orthopaedics Association. The care of fragility fracture patients. London: BOA, 2007.
3 Gates S, Fisher JD, Cooke MW, Carter YH, Lamb SE. Multifactorial assessment and targeted intervention for preventing falls and injuries among older people in community and emergency care settings: systematic review and meta-analysis. BM/ 2008;336:130-3. (19 January.)

4 Lamb S, Gates S, Fisher J, Cooke M, Carter Y, McCabe C. Scoping exercise on fallers' clinics: report to the National Co-ordinating Centre for NHS Service Delivery and Organisation R\& D (NCCSDO). www.sdo.lshtm.ac.uk/ sdo1392006.html

5 Clinical Effectiveness and Evaluation Unit. National clinical audit of falls and bone health. London, 2007. www.rcplondon.ac.uk/COLLEGE/ceeu/fbhop/fbhopnationalreport.pdf

\section{Direct intervention is needed}

Gates et al conclude that the evidence base is weak for the effectiveness of multifactorial interventions to prevent falls in primary care, the community, and emergency care. ${ }^{1}$ However, the 19 studies they reviewed are not all trials of multifactorial assessments and targeted interventions.

These 19 trials require sorting into three more clinically relevant groups: those that are not truly multifactorial (three), those entailing assessment and referral but no direct intervention (10), and those entailing multifactorial assessment and direct intervention (six).

Analysed in this way, four of the six trials in the more important third group are either clearly positive or had a favourable risk ratio but insufficient power, and only two were negative. Seven of the 10 trials of assessment and referral, but without direct intervention, were negative. In one of the three trials of physical therapy, falls were not a primary or secondary outcome measure, so it should not be considered a fall prevention trial.

When similar trials are grouped together, the importance and effectiveness of direct intervention for multiple risk factors is seen for preventing falls. ${ }^{2}$

Barney S Spivack medical director, LifeCare, Shelton, CT 06484, USA bspivack@lifecare.com Competing interests: None declared.

1 Gates S, Fisher ID, Cooke MW, Carter YH, Lamb SE. Multifactorial assessment and targeted intervention for preventing falls and injuries among older people in community and emergency care settings: systematic review and meta-analysis. BM/2008;336:130-3. (19 January.)

1 Chang JT, Morton SC, Rubenstein ZL, Mojica WA, Maglione M, Suttorp M), et al. Interventions for the prevention of falls in older adults: systematic review and meta-analysis of randomised clinical trials. $B M$ ) 2004;328:680

\section{Try the stork challenge}

Järvinen et al say that the risk of falls remains largely overlooked in clinical practice because it is difficult to assess. ${ }^{1}$ We developed an exercise walkway for patients to use during outpatient visits. This consists of a series of 10 balance, breathing, and stretching exercises. The walkway starts and finishes with the "stork test": a static balance test on one leg, with closed eyes. How long a person can stand on one leg, with eyes closed, is a direct measure of his or her balance and hence their risk of falls. ${ }^{2}$ We introduced the stork test to engage and motivate people to continue exercising.

We piloted the walkway with 108 people (57 patients, 16 relatives, 35 staff; 28 male; mean age 55 (13-85)). With the help of a trained volunteer, participants completed the walkway exercises and answered an anonymous questionnaire, documenting the stork test measurements and asking about demographics, previous exercise, and motivation to further exercise. The stork test time decreased with age and improved after the exercises. The overall mean times improved from $13.2 \mathrm{~s}$ to $18.4 \mathrm{~s}$ ( $\mathrm{P}<0.001)$. The number with stork test times of less than $4 \mathrm{~s}$ decreased from 25 before exercise to 10 after exercise ( $P<0.001)$. Three quarters of them thought that they would continue the exercises at home, two thirds saying that they had been influenced by the stork test.

Relatives and friends are invited to take part with patients as this helps overcome the embarrassment of exercising in a public place and encourages them to continue the exercises together at home.

Lyn Williamson consultant rheumatologist, Rheumatology Department, Great Western Hospital, Swindon SN6 3BB lyn.williamson@smnhst.nhs.uk

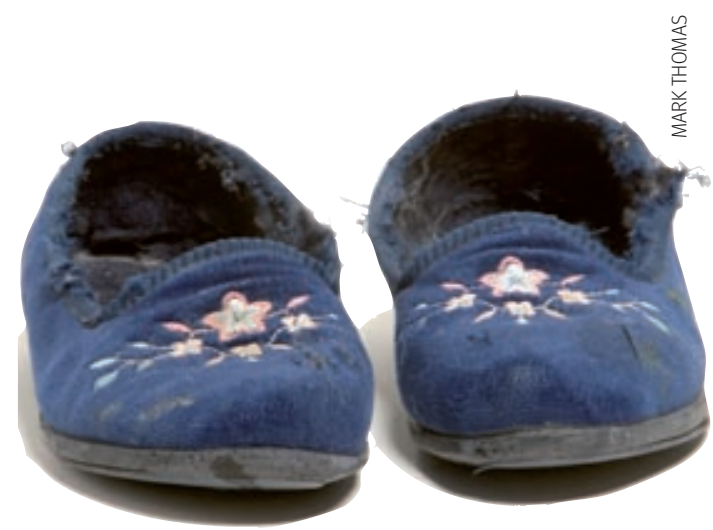


Competing interests: None declared.

1 Järvinen T, Sievanen H, Khan KM, Kannus P. Shifting the focus in fracture prevention from osteoporosis to falls. BM/ 2008;336:124-6. (19 January.)

2 Vellas BJ, Wayne S, Romero L, Baumgartner RN. One-leg balance is an important predictor of injurious falls in older patients. JAm Geriatr Soc 1997;45:735-8.

\section{Don’t forget standing blood pressure}

Postural hypotension is a side effect of many antihypertensive drugs and a well recognised cause of acute or repeated falls. ${ }^{12}$ Measuring standing blood pressure in elderly hypertensive patients is recommended by the British Hypertension Society especially for adjusting treatment. ${ }^{3}$ We looked at 50 consecutive elderly patients aged 78 or older who were admitted to our hospital for falls, acute confusion, or inability to manage at home because of falls.

We studied 28 men and 22 women with an age range of 78-98 and a mean age of 84 . All were treated for hypertension, but standing blood pressure was measured in only 9 of them. In 13 antihypertensive drugs were completely withdrawn, and in 21 these drugs were reduced. Subsequently 35 patients were discharged home but 15 were discharged to residential homes. During hospital stay, 15 patients had recurrent falls. This audit shows that when hypertension is treated in elderly patients, the standing blood pressure should be used to guide pharmacological intervention.

Daniel A Jones ST2 general medicine

Farhad Huwez consultant physician

Basildon and Thurrock University Hospital,

Basildon SS16 5NL

drdajones@hotmail.com

Competing interests: None declared.

1 Gates S, Fisher JD, Cooke MW, Carter YH, Lamb SE. Multifactorial assessment and targeted intervention for preventing falls and injuries among older people in community and emergency care settings: systematic review and meta-analysis. BMJ 2008;336:130-3. (19 January.)

2 Pinto E. Blood pressure and ageing. Postgrad Med J 2007;83:109-14.

3 Mclnnes JFP, Sever PS, Thom SM, Williams B, Poulter NR, Brown MJ, et al. British Hypertension Society guidelines for hypertension management 2004 (BHS-IV). BMJ 2004;328:634-40.

\section{MEASURING PATIENT CARE}

\section{PROMs promote health gain and patient involvement}

Hawkes seems to have swallowed the paternalistic line that what doctors do to patients is more important than the outcome as perceived by them. ${ }^{1}$ How can we know if a process brings benefits and continues to improve it without measuring the outcome, and how can we rely on process alone when the evidence shows such widespread variation and inconsistency in process in clinical practice? For patients, there is much more to success than alive or dead. How often have we heard: "They said my hip replacement went well, but I am now housebound" or "He says I have a good flow rate in my bypass graft, but I still get pain at 10 metres"?

Patient reported outcome measures (PROMs), unlike most of the other clinical measures used traditionally (readmissions, infection rates, adverse incidents, etc), usually measure health gain-what actually happens to most patients who interface with the healthcare system. BUPA Hospitals (now Spire Healthcare) have been using PROMs for years, and the high response rates now achieved show just how much value patients put on being asked about their outcome.

Our work (using Outcome Technologies) and that of others is described in Browne et al's recent paper. ${ }^{2}$ Routine measurement of patient reported outcome is quite easy to do and cost efficient. We are convinced that it can encourage continuous quality improvement and that the data when made available (properly risk adjusted) can help general practitioners and their patients make more informed choices about providers. We were delighted to see PROMs promoted in the NHS operating framework $^{3}$ and also supported by the Royal College of Surgeons of England. We believe they will reduce the noise in the system, make it more transparent, and help give patients the real say in their health care that they deserve.

Andrew J Vallance-Owen group medical director BUPA, London WC1A2BA vallanca@bupa.com Competing interests: Outcome Technologies is a BUPA subsidiary.

1 Hawkes N. How do we get the measure of patient care? BMJ 2008;336:249.(2 February.)

2 Browne J, Black N, et al. Report to the Department of Health. Patient reported outcome measures in elective surgery. www.lsthm.ac.uk/hsru/research/PROMs Report-12-Dec-07.pdf

3 Department of Health. The NHS in England: The operating framework for 2008/9. London: $\mathrm{DoH}$.

\section{OSTEOARTHRITIS OF THE KNEE}

\section{Topical NSAIDs have unknown effectiveness}

Dieppe claimed in an editorial about osteoarthritis that topical non-steroidal antiinflammatory drugs (NSAIDs) are as effective as oral NSAIDs. ${ }^{1}$ He refers to a report from the National Institute for Health and Clinical Excellence (NICE), which describes two metaanalyses. He notes that the authors assessed the trials for quality, but the 424 page report says nothing about that quality. The authors of

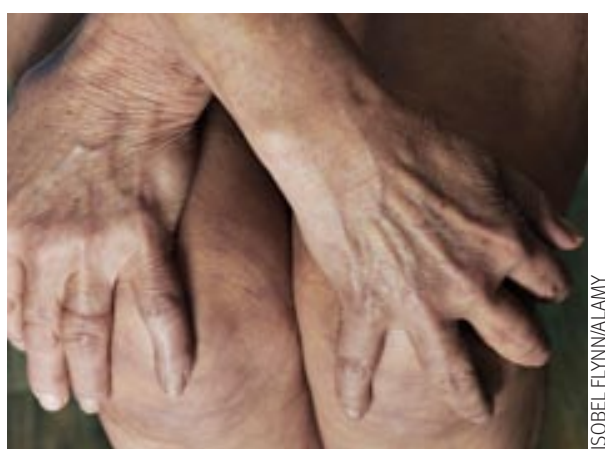

one the meta-analyses, however, reported that the trials were of poor quality and that the effect decreased with increasing sample size of the trials. ${ }^{2}$ There are other problems with the trials, and the results are difficult to interpret.

Dieppe also quotes a systematic review of topical NSAIDs in people with musculoskeletal pain. The authors reported that small trials exaggerated the effects. When some of the same authors updated this review in people with acute musculoskeletal pain, the effect again decreased significantly and substantially with increasing sample size of the trials. ${ }^{3}$ However, they paid no attention to this problem as their results build on all the trials, although I pointed out that this was a major compulsory revision they needed to do when I peer reviewed their manuscript. ${ }^{4}$ Their trials were also subject to enormous statistical heterogeneity, but again, the authors refused to pay any attention to this fundamental problem. Their reply to the peer review comments ${ }^{4}$ is interesting as it shows that their review is of very poor quality and that its authors did not take account of the most basic methodological evidence that exists for performing systematic reviews, even though this was pointed out to them.

I have described these issues in my chapter on NSAIDs in Clinical Evidence, ${ }^{5}$ and I have concluded, in accordance with the evidence categories, that topical NSAIDs have unknown effectiveness.

Peter C Gøtzsche director, Nordic Cochrane Centre Rigshospitalet, Department 3343, DK-2100 Copenhagen Ø, Denmark pcg@cochrane.dk

Competing interests: None declared.

1 Dieppe P. Osteoarthritis of the knee in primary care: Topical NSAIDs are as effective as oral NSAIDs, and patients prefer them. BMJ 2008;336:105-6. (19 January.)

2 Lin J, Zhang W, Jones A, Doherty M. Efficacy of topical non-steroidal anti-inflammatory drugs in the treatment of osteoarthritis: meta-analysis of randomised controlled trials. BMJ 2004;329:324-6.

3 Mason L, Moore RA, Edwards JE, Derry S, McQuay HJ. Topical NSAIDs for acute pain: a meta-analysis. BMC Fam Pract 2004;5:10.

4 Prepublication history for: Mason L, Moore RA, Edwards JE, et al. Topical NSAIDs for acute pain: a meta-analysis. BMC Fam Pract 2004;5:10.www. biomedcentral. com/1471-2296/5/10/prepub.

5 Gøtzsche PC. NSAIDs. http://clinicalevidence.bmj.com/ ceweb/conditions/msd/1108/1108.jsp. Published 1 June 2007. 
PRESUMED CONSENT No such thing

There is no such thing as "presumed consent for organ donation." ${ }^{1}$ Presumed consent isn't consent at all. Without consent organs are taken, not donated. I don't have a problem about my organs being taken-but many will.

As section 15 of the Code of Practice of the Human Tissue Act reminds us, consent is at the heart of the act for the removal and use of human organs-and rightly so.

Compulsory voting in Australia means that all adults are mandated to choose their parliamentary representatives; a mandated choice by law. There is no opt in or opt out. It is accepted and it works. If we are serious about the organ shortage and serious about consent, we should mandate all adults to choose what to do with their organs. There could even be a "can't decide now" box-equivalent to a spoilt ballot paper. A policy of mandated choice would remove all debate around opt in, opt out, soft or hard, or the bureaucracy and regular publicity about registering objection. The current "opt in" could continue for children.

If we believe that citizenship creates some minimal duties to each other, and if we believe in real consent, mandated choice offers us a better way forward than the deceits of "presumed consent."

This is a personal view and does not represent the opinion of the RCP or its ethical issues committee.

John Saunders honorary professor, Centre for Philosophy, Humanities and Law in Healthcare, University of Wales Swansea, Nevill Hall Hospital, Abergavenny NP7 7EG saundersjohn@doctors.org.uk

Competing interests: JS is chair, Committee for Ethical Issues in Medicine, Royal College of Physicians of London.

1 Hamm D, Tizzard J. Presumed consent for organ donation. BMJ 2008;336:230. (2 February.)

\section{A bad choice}

We are given a false choice between opting in and opting out of organ donation. ${ }^{1}$ The current system is not good enough, but opting out is neither the only nor the best answer. Currently the opt-in system is run passively-it relies on people waking up one morning and deciding to plan the details of their death. Most don't. We need a proactive approach: let's ask peopleperhaps when they join a general practice-“Do you want to be an organ donor?" If they say yes then it should be our responsibility to add their details to the register. This interaction could also be an opportunity to suggest that this decision be discussed with the next of kin. This approach is simple and could be much more efficient than an opt-out system that, to remain ethically sound, would require continuous and strenuous efforts to ensure the entire population is informed.

Sarah Boehm senior house officer, Broomfield Hospital, Chelmsford, Essex CM17ET sarahdaisyboehm@yahoo.com Competing interests: None declared.

1 Hamm D, Tizzard J. Presumed consent for organ donation. BMJ 2008;336:230. (2 February.)

\section{SAFETY AND THE FLYING DOCTOR}

\section{Not just about working hours}

Cappuccio and Lockley are over-simplifying a complex situation. ${ }^{1}$ Since the European Working Time Directive (EWTD) was introduced, consistent concerns have been raised regarding the reduced time that is available for training junior doctors, and the effect that this will have on both clinical experience and quality of care. ${ }^{2}$ Of particular note, the 2007 National Confidential Enquiry into Patient Outcome and Death (www.ncepod.org.uk), which identified deficiencies in the care of emergency admissions, reports that because of the current working time constraints of junior doctors, resulting in reduced patient contact, the concern is that they are less able to recognise critically ill patients and act decisively. Many examples of this were seen throughout this study.

The inevitable trend of the EWTD is more shifts of shorter duration: doctors spend more days in the hospital and have shorter periods away from work to relax and spend time with family and friends. This is overwhelmingly unpopular with surgical trainees, some of whom have made informal arrangements to breach the EWTD in order to improve their quality of life, while calling for a derogation that will allow a return to the previous on-call system. ${ }^{3}$

Multiple short shifts require multiple handovers, each one introducing inefficiency and new opportunities for error. Both doctors and patients prefer continuity of care, and the ability to see a patient throughout the course of their illness. ${ }^{3}$ Junior doctors no longer function in traditional teams, rarely receive consistent supervision, and are demoralised by working arrangements that prevent them from forming stable relationships with their patients. Coupled with current uncertainties in training, it is hardly surprising that absenteeism has tripled among juniors in the past few years; a sure sign of declining job satisfaction. ${ }^{4}$

Jonathan R Benger consultant in emergency medicine United Bristol Healthcare Trust, Bristol BS1 3NU Jonathan.Benger@ubht.nhs.uk

Competing interests: None declared.

1 Cappuccio FP, Lockley SW. Safety and the flying doctor. BMJ 2008;336:218. (26 January.)

2 Kara N, Patil PV, Shimi SM. Changes in working patterns hit emergency general surgical training. Ann R Coll Surg Engl 2008;90(suppl):60-3.

3 Grover K, Gatt M, MacFie J. The effect of the EWTD on surgical SpRs: a regional survey. Ann R Coll Surg Engl 2008;90(suppl):68-70.

4 Mattioli M, Michulitis G, Perry EP. MMC and absenteeism. Ann R Coll Surg Engl 2008;90(suppl):35.

\section{MANAGING “PROBLEM” JUNIORS}

\section{Practical advice is available}

Practical advice for managing doctors in difficulty has just been published by the National Association of Clinical Tutors (2008). ${ }^{12}$ It provides a comprehensive diagnostic framework for formulating problems and suggests appropriate management options. The approach used is systematic and consistent and makes reference to the National Clinical Assessment Service. I would commend this resource to UK medical educationalists as their first port of call.

Kelwyn D Williams consultant psychiatrist

Gloucester GL13NW kelwyn.williams@glos.nhs.uk Competing interests: None declared.

1 Steinert Y. The "problem" junior: whose problem is it? BM/ 2008;336:150-3. (19 January.)

2 National Association of Clinical Tutors. Doctors in difficulty. Managing trainees in difficult. Practical advice for educational and clinical supervisors, January 2008. www.nact.org.uk/did.html

\section{DRUG COMPANY PAYMENTS}

\section{Put declaration in abstracts}

Taylor argues that speakers should declare funding. ${ }^{1}$ Most journals now demand competing interest to be declared in a full article, but when the abstract of the paper is published on Medline or elsewhere the declaration disappears. We all know that students, journalists, or others should read the full article, but the fact is that many people only read the abstract of many papers. Conflict of interest should always be included-including in an abstract.

Rosemary Stanton visiting fellow, School of Medicine, University of New South Wales, Kangaroo Valley, NSW 2577, Australia

rstanton@snoopashoal.com

Competing interests: None declared.

1 Taylor MS. Speakers should declare funding. BMJ 2008;336:234. (2 February.) 


\section{DOUBLE BLIND PEER REVIEW}

\section{Response rate was only $7.7 \%$}

I am very surprised at both the headline and the way in which this survey of double blind peer review was reported. ${ }^{1}$ The survey had a response rate of only $7.7 \%$. In fact, $71 \%$ of the $7.7 \%$ who responded said that such reviews are fairer and more objective, which by a very rough calculation amounts to fewer than $6 \%$ of the people contacted. The survey is so unrepresentative as to be of no interest. By reporting it in this way, you have made it misleading.

Anne Szarewski clinical consultant

Wolfson Institute of Preventive Medicine, London EC1M 6BO anne.szarewski@cancer.org.uk

Competing interests: None declared.

1 Kmietowicz Z. Double blind peer reviews are fairer and more objective, say academics. BMJ 2008;336:241. (2 February.)

\section{INGUINAL HERNIAS}

\section{Is treatment needed?}

The advice to offer surgery to all fit patients with asymptomatic inguinal hernias ${ }^{1}$ seems to conflict with some of the evidence.

A case can be made for watchful waiting, which is less costly and avoids the risks associated with surgery. ${ }^{2}$

Stephen Head general practice performer Middleton Lodge, New Ollerton, Newark, Nottinghamshire NG229SZ shead@doctors.org.uk

Competing interests: None declared.

1 Jenkins JT, O'Dwyer PJ. Inguinal hernias. BM] 2008;336:269-72. (2 February.)

2 Fitzgibbons RJ, Giobbie-Hurder A, Gibbs JO, Dunlop DD, Reda DJ, McCarthy M, et al. Watchful waiting vs repair of inguinal hernia in minimally symptomatic men: randomized clinical trial. JAMA 2006;295:285-92.

\section{A case of waste not, want not?}

In answer to Head (previous letter), is inguinal hernia repair perhaps like tonsillectomy used to be? ${ }^{1}$ That is, the surgeon can do the operation, so the surgeon does the operation? Might this be a case of "waste not, want not"?

John G Gooderham member, West Sussex Patient and

Public Involvement Forum (PPIF)

Billingshurst, West Sussex RH14 9TJ

sue@goodiehouse.wanadoo.co.uk

Competing interests: None declared.

1 Jenkins JT, O'Dwyer PJ. Inguinal hernias. BMJ 2008;336:269-72. (2 February.)

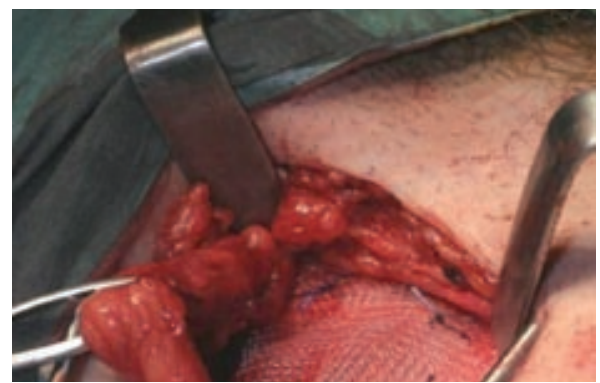

\section{WORKWEAR FOR DOCTORS}

\section{1 uses for a white coat}

The government is trying to ban doctors in the United Kingdom from wearing white coats in hospitals, ${ }^{1}$ the only country in the world where this has happened. Although there is no logic or evidence to support this policy, ${ }^{2}$ no doubt there will be many thousands of white coats lying idle in hospital laundries. Rather than throwing them away, we tried to think of how they could be recycled. We were hoping to think of 101 uses for a white coat. Here are 31:

1 Use it as a projector screen

2 Donate it to developing countries

3 Give it to any developed country apart from the UK

4 Give it to the butcher

5 Give it to the dentist

6 Cut it up into handkerchiefs

7 Turn it into nappies

8 Make sails out of it

9 Make it into dusters or dishcloths

10 Give it to a pharmacist

11 Turn it into napkins

12 Use it for a shadow theatre screen

13 Give it to your child for a school play

14 Donate it to a science museum

15 Give it to the Catholic Church for priest collars

16 Give it to the Catholic Church for nuns' head covers

17 Turn it into hair ribbons

18 Turn it into curtains

19 Turn it into a demonstration banner

20 Wave it as a white flag in case of surrender

21 Use as a dust sheet when you are painting the house

22 Give it to your child to play doctors and nurses

23 Cut it into bandages

24 Donate it to the local abattoir

25 Use for white balance for endoscopy camera

26 Make it into a scarecrow

27 Make it into a windshield for the summer holidays

28 Wear it at a fancy dress party

29 Give it to the local school dinner lady

30 Donate it to the local laboratory

31 Give it to your vet.

Adam Magos consultant gynaecologist, Royal Free Hospital, London NW32QG a.magos@medsch.ucl.ac.uk

Other authors are Nawar Al-Shabibi, Angeliki Papadimitriou, Sheethal Madari, loannis Korkontzelos, Andreas Stavroulis, Ali Nakash, Nikolaos Gkioulekas, Charalampos Stamatopoulos, Stylianos Triantafyllidis, Michail Fragoulidis.

Competing interests: None declared.

1 Department of Health. Uniforms and workwear: an evidence base for developing local policy. London: DoH, 2007

2 Magos A, Maclean A, Baker D, Goddard N, Ogunbiyi O. A cheap soundbite. $B M J 2007 ; 335: 684$. (6 October.)

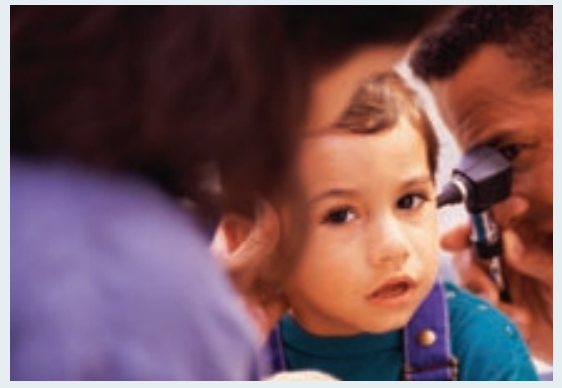

\section{GPS CRITICISE OTALGIA ARTICLE}

\section{Extracts from responses}

We get no sense of the frequency or incidence of symptoms in this 10 minute consultation article on otalgia. ${ }^{1}$ Instead we are presented with a list that gives no sense of perspective. As every practitioner knows, most cases of otalgia are the result of self limiting viral infections. Most of the remaining cases are often without physical signs, and the pain comes from the oropharynx or the Eustachian tube (which was not even mentioned by the authors)

James $\mathrm{N}$ Hardy London

The article on otalgia does not offer some really useful short cuts to help with ear pain.

Wiggling the pinna is sore in otitis externa, not otitis media (sometimes difficult to differentiate if the external auditory meatus is full of debris).

Getting patients to "pop" their ears is a useful way of seeing if the pain is middle ear in origin. A negative Rinne test is helpful when diagnosing otitis media (how can they have otitis media with an air filled middle ear?). James A Cave Newbury

The instruction to prescribe antibiotics for all patients with acute otitis media in the 10-minute consultation contradicts guidance published elsewhere, which indicates that antibiotics should not be prescribed in most cases. ${ }^{1}$ Educating patients, in particular parents of small children, that all earache does not need to be seen by a GP or out of hours doctor has workload implications. John M Reay Scarborough

If I were to use antibiotics, especially co-amoxiclav, as first line treatment in otalgia, as recommended, ${ }^{1}$ this would contribute to bacterial resistance and a higher rate of Clostridium difficile colitis in the community.

Bruno Capone Tunbridge Wells

1 Siddiq MA, Samra MJ. Otalgia. BMJ 2008;336:276-7. (2 February.)

Full author details are available on bmj.com 